\title{
Infundibulopelvic stenosis-multicystic kidney syndrome
}

INSERM

\section{Source}

INSERM. (1999). Orphanet: an online rare disease and orphan drug data base.

Infundibulopelvic stenosis-multicystic kidney syndrome. ORPHA:1849

Infundibulopelvic stenosis-multicystic kidney syndrome is a rare, genetic renal

malformation syndrome characterized by variable degrees of malformation in the pelvicalyceal system (including unilateral or bilateral calyceal dilatation, infundibular stenosis, hypoplasia or stenosis of the renal pelvis) which lead to multicystic kidney. Clinically it exhibits abdominal, lumbar or flank pain, recurrent urinary tract infections, hypertension, proteinuria and often prog resses to renal insufficiency. Calyceal dilatation and hydronephrosis are frequently seen on imaging. 